\title{
Fibre Fraction Effects on Thermal Degradation Behaviour of GFRP, CFRP and Hybrid Composites
}

\author{
A. VANAJA AND R.M.V.G.K. RAO* \\ FRP Pilot Plant Unit \\ National Aerospace Laboratories \\ Kodihalli, Bangalore, 560017, India
}

\begin{abstract}
The effects of fibre fraction on thermal degradation of composites containing glass, carbon and glass/carbon hybrid reinforcements in a bifunctional epoxy resin system were studied. Thermogravimetric technique was used to monitor the weight loss with the temperature. The degradation patterns so obtained were correlated with the fibre fraction of the composites.
\end{abstract}

KEY WORDS: GFRP, CFRP, hybrid composites, fibre fraction, thermal degradation, thermogravimetric analysis (TGA).

\section{INTROODUCTION}

ClASS AND CARBON fibre reinforced epoxy composites are widely used I in a number of aerospace and non-aerospace applications. Selection of reinforcements and matrix systems, as well as the fibre fraction is crucial in structural designing of the composite product for specific applications. On the other hand, thermal stability and hot wet property retention are the matrix dominated deciding factors that govern the long term performance capabilitics of the composites.

Glass fibres are better known for their toughness, medium modulus, strength and stability, but are unsuitable for use in fatigue resistant composites, while carbon fibres are characterized by high modulus, brittleness, low density and superior fatigue properties. However, carbon fibres are thermally less stable and have lower toughness when compared to

*Author to whom correspondence should be addressed. E-mail: karger@ivw.uni-kl.de

Journal of REINIOORCED PLASTICS AND COMPOSites, Vol. 21, No. 15/20)2

0731-6844/02/15 1389-10\$10.00/0 DOI: 10.1106/073168402023780

(c) 2002 Sage Publications 
glass fibres [1]. Hence, to tailor the properties for balanced performance requirements, fibre hybridization has recently become an attractive approach $[2,3]$. Hybrid fibre reinforced composite materials can be made in two ways.

1. By mixing the fibres (co-mingling) in a common matrix

2. By laminating alternate layers of each type of reinforcement

The thermal stability of a given composite is further governed by the matrix functionality and cure temperature. Also, for a given fiber/resin system, the thermal degradation behaviour depends on the fibre fraction (in a way on the matrix content) since at higher temperatures of exposure it is the matrix which practically degrades.

The objective of this work therefore, is to study the effect, of fibre fraction on the thermal behaviour of composites containing glass, carbon and glass/ carbon hybrid reinforcement in a bifunctional epoxy resin system. The Thermogravimetric Analysis technique (TGA) has been chosen and adopted to monitor the behaviour as it best represents the composite's weight loss (which is mainly due to matrix loss) with temperature.

In the present study, Glass Fibre Reinforced Plastic composites (GFRP), Carbon Fibre Reinforced Plastic composites (CFRP) and their hybrid composites of different fibre fractions were subjected to thermal degradation in a TGA furnace under nitrogen atmosphere to avoid any oxidation effects and respective thermograms were recorded. As the thermograms so obtained showed distinctly different characteristics mainly in relation to the final losses beyond $400^{\circ} \mathrm{C}$, a correlation emerged between the fibre fractions and their thermograms, clearly reflecting characteristic degradation trends. The fibre fractions were also measured by the conventional techniques namely, the resin burnout test for GFRP and acid digestion method for CFRP. An empirical relationship based on mixture rule has been employed to calculate the fibre fraction of a given composite from the thermogravimetric data. Through the studies presented, it is hoped that the fibre fractions of composites, especially those of CFRP, can be determined in a simple way using TGA technique avoiding the cumbersome chemical methods presently used for composites.

\section{EXPERIMENTAL DETAILS}

\section{Materials}

Epoxy resin system chosen is LY5052/HY5052 (Ciba Speciality Chemicals Ltd.). The reinforcements were unidirectional (UD) carbon tape (Anchor Reinforcements, USA), bidirectional (BID) carbon fabric (HEXCEL) and BID glass fabric (CS Interglass, UK). 


\section{Specimen Preparation}

Neat resin casting: Epoxy resin and hardener were mixed in stoichiometric ratio and the mixture was degassed before curing. The degassed mixture was cast between stainless steel moulds covered with Teflon sheets eliminating the use of releasing agents and thereby avoiding possible contamination of the resin. The system was allowed to cure at room temperature and was post cured in a step-wise manner $\left(50^{\circ} \mathrm{C} / 0.5 \mathrm{~h}, 70^{\circ} \mathrm{C} / 1 \mathrm{~h}\right.$, and $\left.85^{\circ} \mathrm{C} / 2 \mathrm{~h}\right)$, ensuring that the glass transition temperature always led the post cure temperalure.

\section{Preparation of Composite Laminates (GFRP, CFRP and Hybrid)}

CFRP laminates with UD carbon tape as reinforcement, GFRP laminates with BID glass as reinforcement and hybrid laminates with BID carbon/ BID glass reinforcements were fabricated using room temperature vacuum bag moulding technique (RTVBM). These laminates were cured at room temperature for $24 \mathrm{~h}$, followed by a step post cure process as mentioned carlier.

The global weight fraction of the cured composites were determined by using gross weights of the constituents (fibre and resin) taken during fabrication. The actual (local) weight fractions of the composites were determined by acid digestion method (ASTM D3171-76) for CFRP laminates and by resin burn out test (ASTM D 2584-68) for GFRP laminates. Table 1 shows the details of different test laminates fabricated.

TGA Technique

The composites were cut into small test specimens and placed in the TGA pan. Dynamic TGA thermograms were recorded using TGA 2950 of TA

Table 1. Detalls of lamlnates fabrlcated.

\begin{tabular}{ll}
\hline Laminate Code & \multicolumn{1}{c}{ Description } \\
\hline UDCFRP 1 & Composite with epoxy resin relnforced with UD Carbon tape \\
UDCFRP 2 & Composite with epoxy resin relnforced with UD Carbon tape \\
UDCFRP 3 & Composite with epoxy resin reinforced with UD Carbon tape \\
UDCFRP 4 & Composite with epoxy resin reinforced with UD Carbon tape \\
BIDGFRP 1 & Composite with epoxy resin reinforced with BID Glass \\
BIDGFRP 2 & Composite with epoxy resin reinforced with BID Glass \\
HYBICG 1 & Composite with epoxy resin relnforced with BID Carbon and BID Glass \\
HYBICG 2 & Composite with epoxy resin reinforced with BID Carbon and BID Glass \\
HYBICG 3 & Composite with epoxy resin relnforced with BID Carbon and BID Glass \\
HYBICG 4 & Composite with epoxy resin reinforced with BID Carbon and BID Glass
\end{tabular}

$W$, values were chosen in the range of $0.45-0.80$. 
Instruments, USA. All experiments were conducted from $50^{\circ} \mathrm{C}$ to $600^{\circ} \mathrm{C}$ at a heating rate of $20^{\circ} \mathrm{C}$ per minute under inert atmosphere. Figures 1-4 represent the thermograms of composite constituents, CFRP, GFRP and hybrid composites respectively.

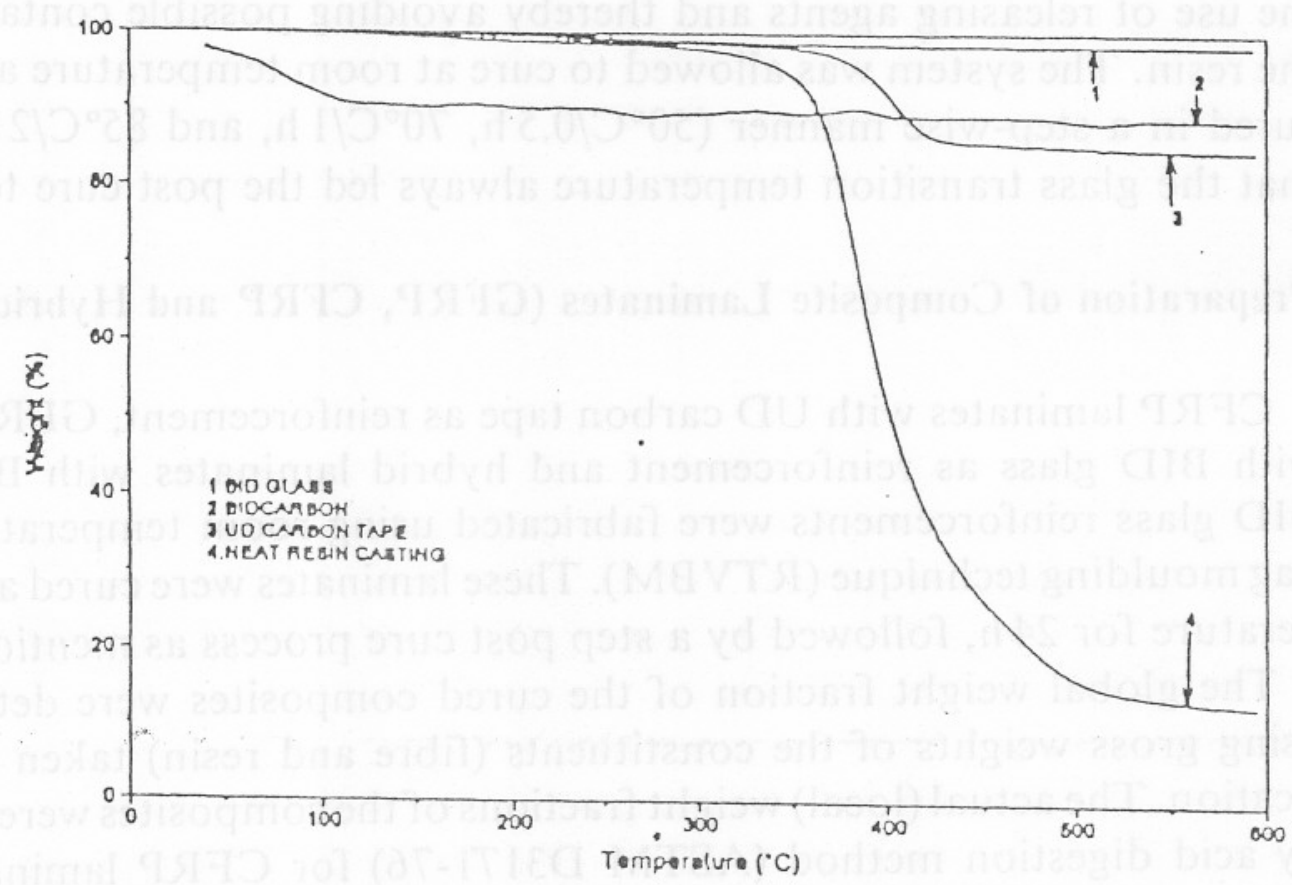

Flgure 1. Thermograms of constituent materials of tho composites.

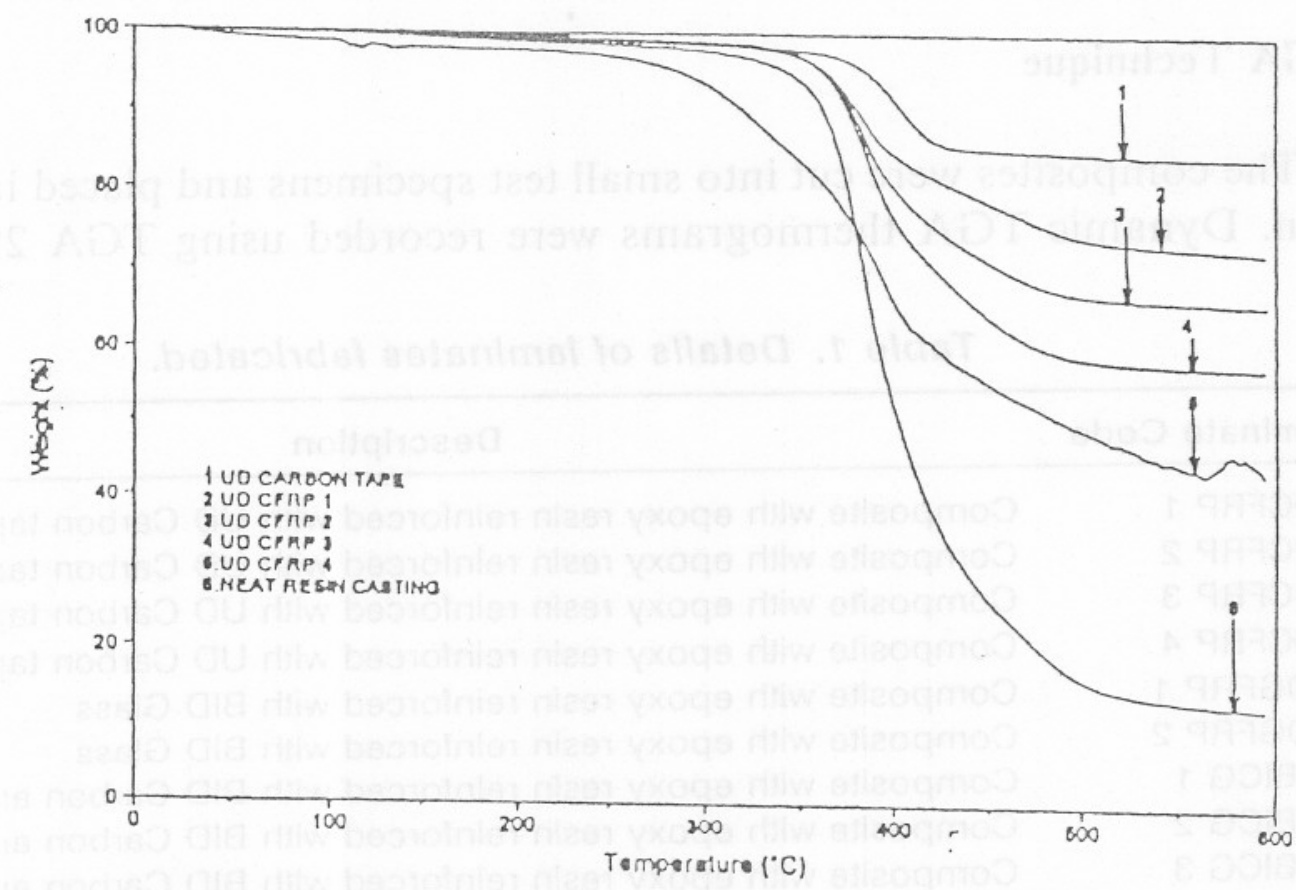

Figure 2. Degradation curves of CFRP composites in comparison with UD carbon tape and noat resin casting. 


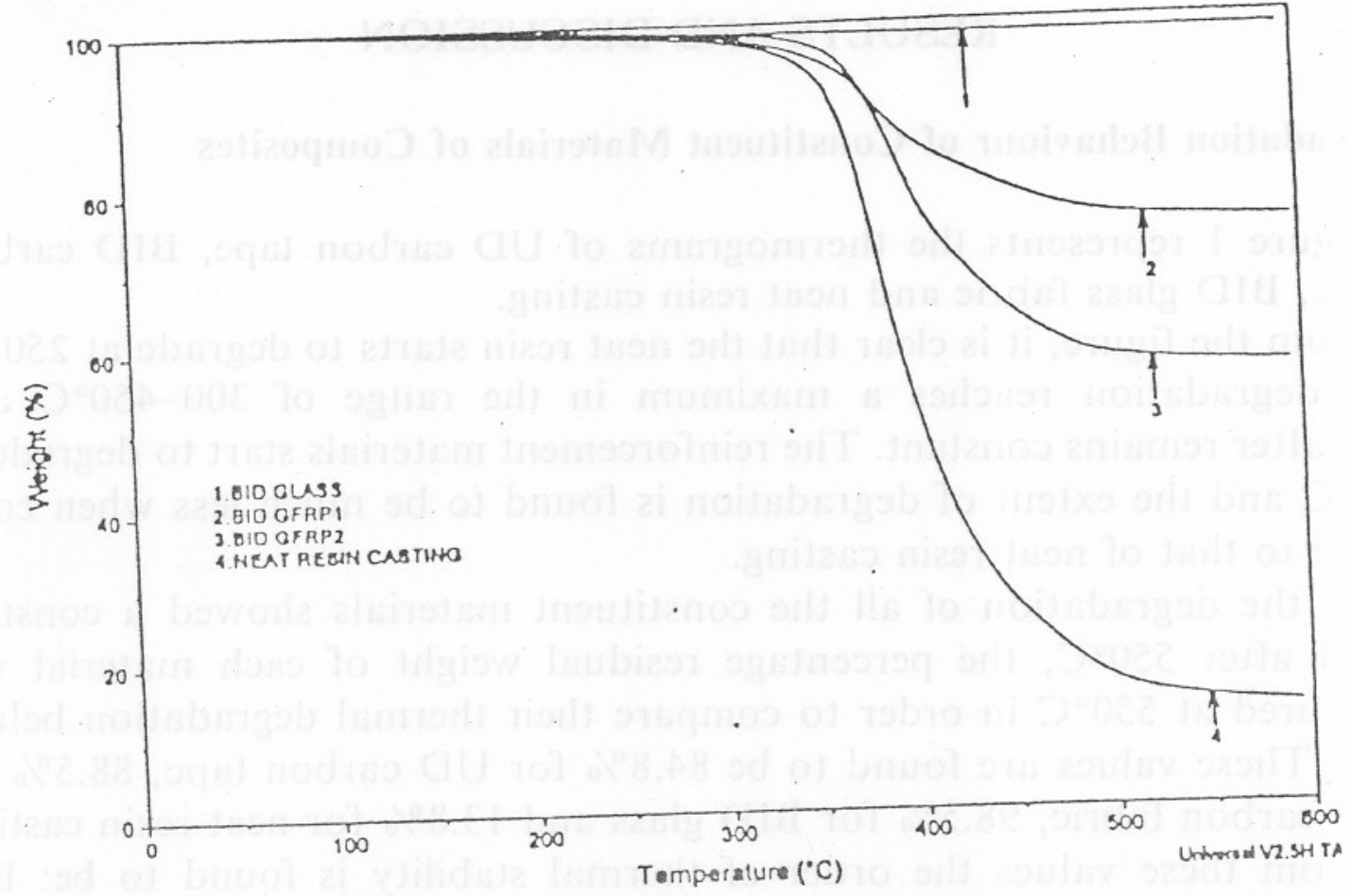

Figure 3. Degradation curves of GFRP composites in comparison with BID glass and neat resin casting.

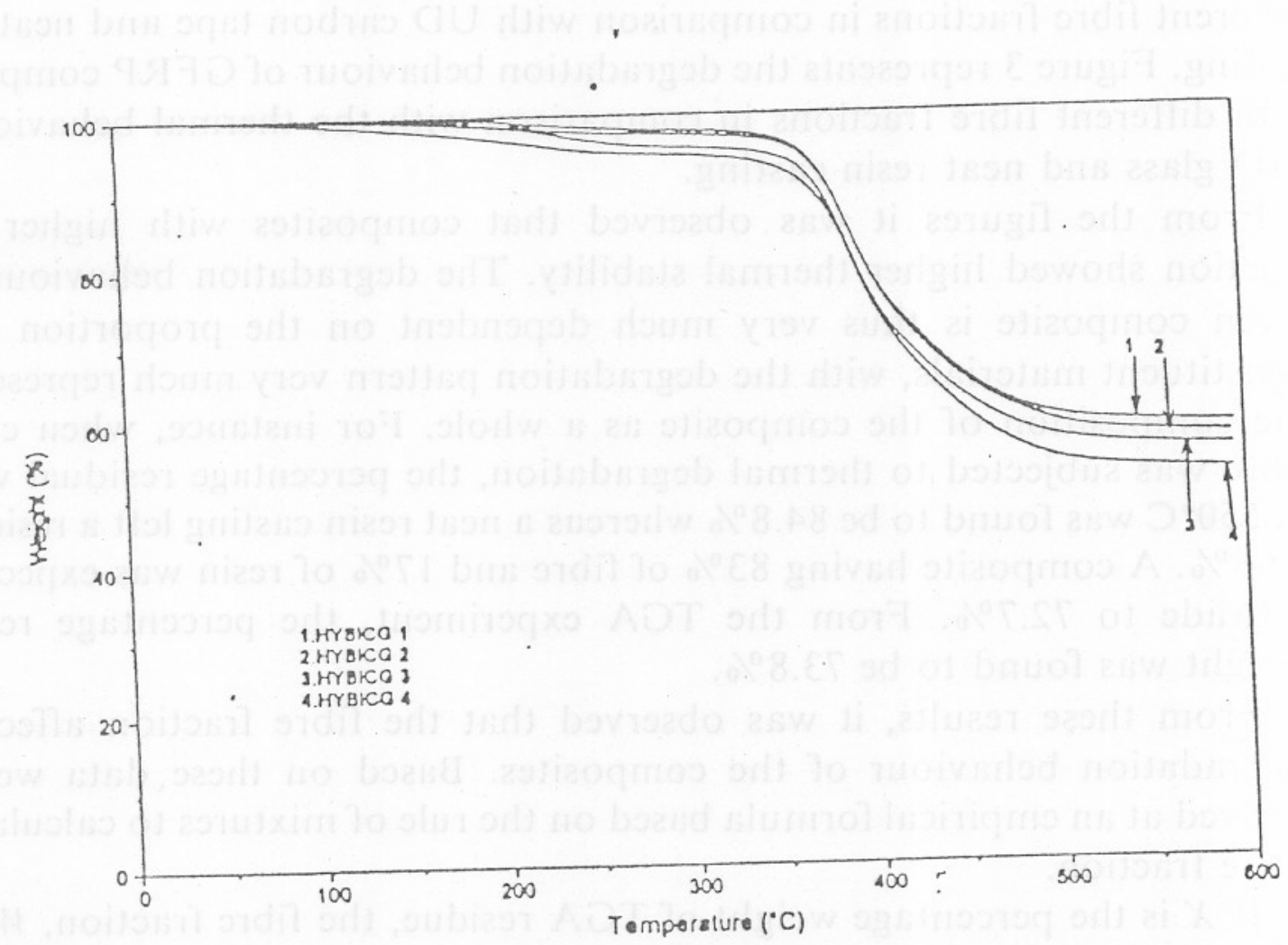

Flgure 4. Thermal degradation behavlour of hybrid laminatos. 


\section{RESULTS AND DISCUSSION}

\section{Degradation Behaviour of Constituent Materials of Composites}

Figure 1 represents the thermograms of UD carbon tape, BID carbon fabric, BID glass fabric and neat resin casting.

From the ligure, it is clear that the neat resin starts to degrade at $250^{\circ} \mathrm{C}$. The degradation reaches a maximum in the range of $300-450^{\circ} \mathrm{C}$ and thereafter remains constant. The reinforcement materials start to degrade at $300^{\circ} \mathrm{C}$ and the extent of degradation is found to be much less when compared to that of neat resin casting.

As the degradation of all the constituent materials showed a constant trend after $550^{\circ} \mathrm{C}$, the percentage residual weight of each material was measured at $550^{\circ} \mathrm{C}$ in order to compare their thermal degradation behaviour. These values are found to be $84.8 \%$ for UD carbon tape, $88.5 \%$ for BID carbon fabric, $98.5 \%$ for BID glass and $13.8 \%$ for neat resin casting.

From these values the order of thermal stability is found to be: BID glass > BID carbon > UD carbon $\gg$ neat resin.

\section{Degradation Behaviour of CFRP and GFRP Composites}

Figure 2 shows the degradation curves of UD-CFRP composites with different fibre fractions in comparison with UD carbon tape and neat resin casting. Figure 3 represents the degradation behaviour of GFRP composites with different fibre fractions in comparison with the thermal behaviour of BID glass and neat resin casting.

From the figures it was observed that composites with higher fibre fraction showed higher thermal stability. The degradation behaviour of a given composite is thus very much dependent on the proportion of its constituent materials, with the degradation pattern very much representing the composition of the composite as a whole. For instance, when carbon fibre was subjected to thermal degradation, the pereentage residual weight at $550^{\circ} \mathrm{C}$ was found to be $84.8 \%$ whereas a neat resin casting left a residuc of $13.8 \%$. A composite having $83 \%$ of fibre and $17 \%$ of resin was expected to degrade to $72.7 \%$. From the TGA experiment, the perentage residual weight was found to be $73.8 \%$.

From these results, it was observed that the fibre fraction affects the degradation behaviour of the composites. Based on these, datal we have arrived at an empirical formula based on the rule of mixtures to calculate the fibre fraction.

If $X$ is the percentage weight of TGA residue, the fibre fraction, $W_{f}$, can be calculated by using the equation: 
Table 2. Percentage degradation calculated vs. experimental values for GFRP and CFRP laminates.

\begin{tabular}{lcc}
\hline $\begin{array}{l}\text { Laminate } \\
\text { Code }\end{array}$ & $\begin{array}{c}\text { Welght Fractlon by } \begin{array}{c}\text { ' } \\
\text { Conventional Methods }\end{array} \\
\text { Weight Fraction } \\
\text { by TGA }\end{array}$ \\
\hline UDCFRP 1 & 83 & 84.5 \\
UDCFRP 2 & 76 & 75 \\
UDCFRP 3 & 64 & 63 \\
UDCFRP 4 & 43 & 44 \\
BIDGFRP 1 & 73 & 72.5 \\
BIDGFRP 2 & 50 & 50.6 \\
\hline
\end{tabular}

$$
X=a\left(W_{f}\right)+b\left(1-W_{f}\right)
$$

where, $W_{f}$ is the weight fraction of the fibre, $a$ is the percentage residual weight when $100 \%$ fibre is degraded and $b$ is the percentage residual weight when $100 \%$ neat resin is degraded.

The fibre fraction values calculated using this formula were tabulated and compared with those obtained by conventional methods. Table 2 presents the comparison of $W_{f}$ values obtained by TGA technique with conventional methods. Further, from the thermograms of Figure 1, it is evident that $100 \%$ of UD carbon degrades to $84.8 \%$. Therefore, the percentage of degraded material will be $15.2 \%$, for UD carbon tape, $11.5 \%$ for BID carbon fabric, $1.5 \%$ for BID glass fabric, and $86.2 \%$ for ncat resin casting. Hence, the unit degradations contributed by these materials will be 0.152 , $0.115,0.015$ and 0.862 respectively.

The percentage degradation for a given composite can be calculated using the following equation:

$$
D=d_{f}\left(W_{f_{c}}\right)+d_{r}\left(1-W_{f_{c}}\right)
$$

where $D$ is the percentage degradation, $d_{f}$ is the unit degradation of fibre, $d_{r}$ is the unit degradation of Resin and $W_{f_{c}}$ is the weight fraction of the fibre determined by conventional method. $D$ can also be calculated from the following equation.

$$
D=(100-X)
$$

where $X$ is the percentage residual weight of the composite obtained at $550^{\circ} \mathrm{C}$ from TGA data.

Table 3 presents the comparison of values obtained by using Equations (2) and (3). They were found to be in good agreement. 
Table 3. Comparison of $W_{f}$ values obtained by conventional methods with those obtalned by TGA data.

\begin{tabular}{lcc}
\hline $\begin{array}{l}\text { Laminate } \\
\text { Code }\end{array}$ & $\begin{array}{c}\text { Calculated \% } \\
\text { Degradatlon Using } \\
\text { Equation (2) }\end{array}$ & $\begin{array}{c}\text { Experimentally } \\
\text { Obtalned \% } \\
\text { Degradation }\end{array}$ \\
\hline UDCFAP 1 & 72.7 & 73.8 \\
UDCFAP 2 & 67.7 & 67.1 \\
UDCFRP 3 & 59.2 & 58.6 \\
UDCFRP 4 & 44.3 & 45.2 \\
BIDGFFP 1 & 75.6 & 75.2 \\
BIDGFPP 2 & 56.1 & 56.7 \\
\hline
\end{tabular}

Degradation Behaviour of Hybrid Laminates

To prove the efficacy of TGA technique, hybrid composites were also analysed according to their composition. Figure 5 represents the lay up sequence of hybrid laminates. Table 4 presents the percentage composition of hybrid laminates prepared. These laminates with varying glass/carbon and resin ratios showed typical degradation bchaviour related to their composition. For example, HYBICG1 composed of $41.84 \%$ glass, $12.06 \%$ carbon and $46.1 \%$ resin is expected to degrade to $58.2 \%$ using Equation (2). Experimentally it was found to be $57.6 \%$. Table 5 presents the percentage degradation calculated using Equation (2) versus experimental values. From the table, it is clear that they are in good agreement.

\section{CONCLUSION}

The effects of fibre fraction on the thermal behaviour of different types of composites based on a DGEBA matrix system were studied. From the

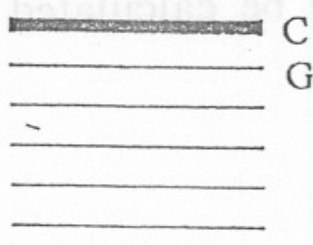

HYBICG 1

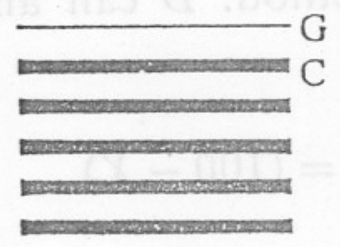

HYBICG2

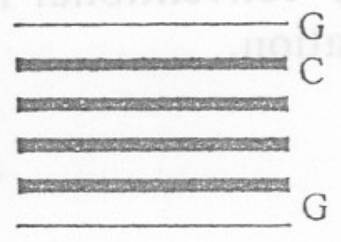

HYBICG3

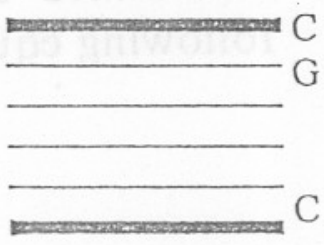

HYBICG4

Flgure 5. Lay-up sequences of hybrid laminates. 
Table 4. Detalls of composition of hybrid laminates.

\begin{tabular}{lccc}
\hline & \multicolumn{3}{c}{$\begin{array}{c}\text { Weight Fraction of Individual Constituents of the } \\
\text { Lybrid Composites (Global) }\end{array}$} \\
\cline { 2 - 4 } Cominate & \% Glass & \% Carbon & \% Resin \\
\hline HYBICG 1 & 41.84 & 12.06 & 46.1 \\
HYBICG 2 & 7.99 & 49.57 & 42.5 \\
HYBICG 3 & 18.8 & 33.40 & 47.8 \\
HYBICG 4 & 16.68 & 36.82 & 46.5 \\
\hline
\end{tabular}

Table 5. Percentage degradatlon calculated vs. experlmental values for hybrld laminates.

\begin{tabular}{lcc}
\hline $\begin{array}{l}\text { Laminate } \\
\text { Code }\end{array}$ & $\begin{array}{c}\text { Calculated \% Degradation } \\
\text { Using Equation (2) }\end{array}$ & $\begin{array}{c}\text { Experimental Obtalned } \\
\% \text { Degradation }\end{array}$ \\
\hline HYBICG 1 & 58.2 & 57.6 \\
HYBICG 2 & 57.5 & 56.2 \\
HYBICG 3 & 54.6 & 52.9 \\
HYBICG 4 & 57.4 & 58.6 \\
\hline
\end{tabular}

results it was observed that the thermal behaviour was dependent on individual constituents of the composites. An empirical relationship proposed based on rule of mixtures was used to calculate the fibre fraction by TGA technique. The values obtained were compared with those by conventional methods. They were found to be in good agreement. The efficacy of TGA technique was verified using hybrid composites also. The degradation behaviour of hybrid laminates was correlated with the weight fraction of the components as calculated using the mixture rule derived.

\section{ACKNOWLEDGEMENT}

The authors are grateful to Dr. T.S. Prahlad, Director, NAL for his support in bringing these studies into a document. They further acknowledge the assistance of Mrs. Sandhya Rao and Mrs. Kavitha of the FRP Pilot Plant.

\section{REFERENCES}

1. Zweben, C. and Norman, J.C. (July 1976). Kevlar $49 /$ Thornel 300 hybrid fabric composites for acrospace applications. SAMPE Quarterly, 1-10. 
2. Bunsell, A.R. and Harris, B. (July, 1974). Hybrid carbon and glass fibre composites. Composites, 157-164.

3. French, A.M. and Pritchard, G. (1992). Environmental stress corrosion of hybrid fibre composites. Composites Science and Tec/mology, 45: 257-263.

4. Wendland, W.W. (1986). Chemical analysis - a series of monographs on analytical chemistry and its applications. Thermal Analysis, 19(3): 195-199.

5. Wendel, T.J. (1978). Critical evaluation of several methods for determining fibre fraction of cured graphite/cpoxy composites. ISAMPE, 23: 160.

6. Annual book of ASTM Standards, (1992). (Revised edition) pp. 35-36. 